Lauren Dodge and Jennifer Sams

\title{
Innovative copyright Unique resources for copyright education
}

earning about or teaching copyright is often frustrating and difficult for both teacher and student because it is a complex area, and, let's face it, reading the text of the law is not always the most exciting way to learn.

Endeavoring to address this issue and many others, the Copyright Education and Consultation Program, a project funded by the Illinois State Library, was designed to establish a program to provide authoritative copyright information directly to faculty, instructors, and researchers at the largest Illinois universities. The goals of the program include increasing confidence in use of materials, informing users of copyright education resources available to them, empowering users with knowledge about their own intellectual property rights, and facilitating use of copyrighted material in the classroom.

While completing this project, many unique and creative copyright resources were discovered that go beyond the traditional, dry text of the law. The resources presented in this article show that copyright education can be engaging and enjoyable. They include videos, interactive tools, comics, podcasts, tutorials, online courses, Twitter feeds, and blogs about copyright.

\section{Videos}

- A Fair(y) Use Tale. Created by Eric Faden of Bucknell University in 2007, this mashup of Disney video clips explains basic copyright principles. The ten-minute video is a little hard to follow at first, due to its choppy nature, but it is humorous and answers such basic copyright questions as, "What is copyright?" "What things can be copyrighted?" and explains such principles as fair use, copyright duration and the public domain, and the irony of using Disney video clips in this mashup. Access: http://cyberlaw.stanford. edu/documentary-film-program/film/a-fair -y-use-tale/.

- Copyright Basics. This animated video explains the same copyright basics as the Copyright on Campus video, but is based in the workplace. Created in 2009 by the Copyright Clearance Center, this six-minute video details how to share copyrighted material at work while still respecting the rights of content creators. Access: http://learn.copyright. $\mathrm{com} /$ int/cbVideo/.

- Copyright on Campus. Created by the Copyright Clearance Center in 2010, this animated video briefly explains copyright basics for academic librarians. In six minutes, it quickly reviews relevant sections of U.S. copyright law, such as fair use, the

Lauren Dodge is program coordinator for the Copyright Education and Consultation Program, e-mail: Idodge@ illinois.edu, Jennifer Sams is the assistant to the program coordinator for the CopyrightEducation and Consultation Program, e-mail: sams2@illinois.edu at the University of Illinois at Urbana-Champaign University Library (c) 2011 Lauren Dodge and Jennifer Sams 
first sale doctrine, the public domain, and highlights their impact on colleges and universities. Access: http://learn.copyright.com /copyrightoncampus/.

- Copyright, What's Copyright? This charming animated video was created by The Media Education Lab at Temple University. Uploaded in 2009, it advocates for balancing user rights and rights of copyright owners and promotes creativity and creation of new works. The catchy tune and lyrics will be stuck in your head all day. Access: http:// youtu.be/0QiO_H0-ok8/.

- Fair Use \& Copyrights. This video explains copyright, permissions, and fair use basics with a film and documentarian focus. Videomaker.com, a privately owned consumer magazine for video enthusiasts, created this five-minute video in 2009. Access: http://youtu.be/GidwzOYiPlo.

\section{- How YouTube Thinks About Copy-}

right. Margaret Gould Stewart, head of user experience at YouTube, discusses how YouTube thinks about copyright in this fiveminute video. In this 2010 TED talk, Stewart discusses the notion of a "digital rights ecosystem," the definition of mash-ups, how YouTube scans for infringements, and the idea of an "ecosystem of culture." She ends her talk with the statement, "By empowering choice we can create a culture of opportunity . . . Joy is definitely an idea worth spreading." Access: http://www.ted.com/talks/margaret_stewart _how_youtube_thinks_about_copyright. $\mathrm{html} /$.

- Larry Lessig on Laws that Choke Creativity. A popular 2007 TED talk by Lawrence Lessig, director of the Edward J. Safra Foundation Center for Ethics and professor of law at Harvard, who discusses how the law is "strangling creativity." In this 20-minute talk, Lessig discusses such notions as Read-Write (RW) vs. Read-Only (RO) culture and our opportunity to revive the RW culture, recreating and remixing as tools of creativity and literacy for this generation. Lessig calls for common sense in current copyright legislation, and to "enable the ecology of free content." Access: http://www.ted.com/talks/larry_lessig_says _the_law_is_strangling_creativity.html/.

- Remix Culture: Fair Use is Your Friend. This five-minute video from the Center for Social Media at the American University School of Communication introduces the "Code of Best Practices in Fair Use for Online Video," a document created by the Center for Social Media. Created in 2008, the video consists of a mash-up style series of clips from online video and poplar movies, and interviews with members of the Code of Best Practices Committee. Access: http:// centerforsocialmedia.org/fair-use/related -materials/codes/code-best-practices-fair-use -online-video.

- YouTube Copyright School. Created by YouTube in 2011, this five-minute video conveys copyright basics pertaining to sharing videos on YouTube and delivers YouTube policies and processes for copyright violations in a fun format, while advocating for original work and creativity. Access: http:// youtu.be/InzDjH1-9Ns.

\section{You Tube}

\section{Interactive tools}

- Digital Copyright Slider. Using a work's publication date and other information, the digital slider suggests whether permission might be needed to use the work. This helpful tool, created by Michael Brewer (University of Arizona Library) and the ALA Office of Information and Technology Policy, creates a broad picture of the public domain and of copyright term limits. Access: http:// librarycopyright.net/digitalslider/.

- Exceptions for Instructors in Copyright Law. This tool by Michael Brewer and the ALA Office for Information and Technology Policy uses a series of questions to help educators determine whether they can use a copyrighted work in their classroom instruction. There are helpful links to extra informa- 


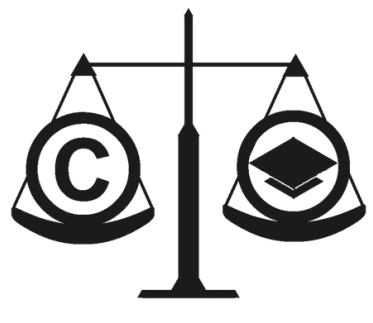

tion, examples, and definitions scattered throughout the questions. $A c$ cess: http://librarycopyright. net/etool/.

- Fair Use

Visualizer. This tool allows the user to input information about the purpose, nature, amount, and market effect of a use. It will then graphically display the information in a way that makes it clear when a use of a copyrighted work might be fair and when it is not. Access: http://www.benedict.com/Info /FairUse/Visualizer/Visualizer.aspx.

- Section 108 Spinner. Section 108 of copyright law allows libraries and archives to make copies of protected works in some situations. This tool explores the laws governing these situations. It cannot cover all of the complexities of the law, but it is a good introduction, and it provides links for further information. Access: http://www. librarycopyright.net/108spinner/.

- Taking the Mystery Out of Copyright. This Library of Congress resource for classroom teachers uses videos, timelines, and interactive FAQs to explain copyright. This is a good introductory tool for students who need a general idea of what copyright law is all about. Access: http://www.loc.gov /teachers/copyrightmystery/\#/copyright/.

- University of Minnesota's Decision Chart. This decision map of yes or no questions is invaluable when faced with a question about legal uses of a work. However, it assumes some existing knowledge of copyright, so it may be better suited for more experienced users. Access: https:// www.lib.umn.edu/sites/default/files/images /UseMapBig.png.

\section{Comics}

- Jolly Roger: A History of Copyright in Cyberspace. This comic narrates the history of copyright and explains the big ideas and concepts

that shape

current copy-

right debate.

While the

comic was

originally

written in

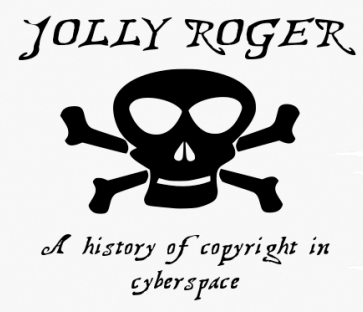

French, the broad focus makes it useful for an audience of any nationality. Access: http:// www.hardabud.com/jollyroger/.

- Tales from the Public Domain: Bound by Law? This digital comic book about the public domain was created through Duke University's Center for the Study of the Public Domain. Interestingly, it incorporates famous images, song lyrics, and quotes into the story as a way to demonstrate fair use. Access: http://www.law.duke.edu/cspd /comics/.

\section{Podcasts}

- Copyright 2.0 Show. Two intellectual property enthusiasts, Jonathan Bailey and Patrick O'Keefe, publish this weekly podcast. During each episode, they discuss current copyright news stories, court cases, and laws with a heavy focus on copyright in the context of technology. The episodes are available as mp3 files. Access: http://www. plagiarismtoday.com/category/podcast/.

PT PlagiarismToday

(ContentTheft|CopyrightInfringement|Plagiarism)

- Fundamentals of Copyright. This series of podcasts features Kenneth Crews, a leading expert in the field of copyright. It is a great tool for building background knowledge of copyright. Each episode is about 20 minutes long and is available through iTunes or as an mp3. Access: http://copyright. columbia.edu/copyright/copyright-in-general /fundamentals-of-copyright/.

\section{Tutorials and online courses}

- Brigham-Young University Tutorial.

This tutorial incorporates three modules that each include learning objectives to help the 
user identify the big ideas behind copyright. After completing the modules, there is a final game that allows you to spin a wheel and answer copyright questions that come up. Access: http://lib.byu.edu/departs/copyright /tutorial/intro/page1.htm.

- Certification in Copyright Management and Leadership. The University of Maryland University College Center for Intellectual Property offers a Certificate in Copyright Management. This certification "provides participants with the knowledge and education sorely needed to navigate the changes in business and education due to the influence of the digital environment." Access: http://www.umuc.edu/cip/.

- Copyright Crash Course Online Tutorial. This tutorial, created by Georgia Harper at the University of Texas, uses videos, graphics, and text to present scenarios that clarify different aspects of copyright that users might encounter. It also includes a test at the end that asks users to apply the knowledge they have gained from the tutorials. Access: http://www.lib.utsystem. edu/copyright/.

- Harvard's Copyright Law for Librarians. Produced by both the Berkman Center for Internet \& Society and Electronic Information for Libraries, this project is essentially a full class on copyright. It is broken into modules that can be mixed and matched depending on the user's needs and interests. The homepage includes suggestions on how to do this. Access: http:// cyber.law.harvard.edu/copyrightforlibrarians/ Main_Page.

- Introduction to Copyright Law. Created in 2006, this online course from Massachusetts Institute of Technology OpenCourseWare is available and free to all. Instructor Keith Winstein introduces copyright law in general, and highlights the basics of legal research and legal citations, fair use, copyright as applied to music, computers, broadcasting, education, file sharing, software licensing, the Library Access to Music Project, and other various relevant topics. Designed to be taught over four weeks, the course includes readings, two assignments, and four 2-hour video lectures. Access: http://ocw.mit.edu /courses/electrical-engineering-and-computer -science/6-912-introduction-to-copyright-law -january-iap-2006/index.htm.

\section{Twitter feeds and blogs}

- ARL Public Policy. Public Policy news from the Association of Research Libraries. Topics covered include copyright and privacy issues. Access: https://twitter.com/\#! /ARLpolicy.

- Copyright Law. Intellectual property news from Michael Scott, professor at Southwestern Law School. Access: https://twitter. com/\#!/CopyrightLaw.

- Copyright Librarian. A blog exploring copyright issues in academic libraries. Written by University of Minnesota copyright librarian, Nancy Sims. Access: http://blog.lib.umn. edu/copyrightlibn/.

- Copyright Office. Information and news from the U.S. Copyright Office. Access: https://twitter.com/\#!/CopyrightOffice.

- Creative Commons. Links and news produced by CreativeCommons.org. Access: https://twitter.com/\#!/creativecommons.

- IPWatch. International intellectual property news. Access: https://twitter.com/\#! /ipwatch.

- IP Law Alerts. News about intellectual property by J. D. Supra, a Web site designed to connect and inform lawyers. Access: https://twitter.com/\#!/IPLawAlerts.

- Kenneth Crews. A Twitter feed by a professor and copyright expert from Columbia University. Access: https://twitter.com/\#! /kcrews.

- Stanford Fairly Used. Tweets from the Stanford Copyright and Fair Use Center. Access: http://twitter.com/\#!/FairlyUsed.

- Techdirt. News that impacts business and innovation. Many, but not all, of their articles deal with copyright and intellectual property. Access: https://twitter.com/\#! /techdirt.

- WIPO News. World Intellectual Property Organization news. Access: https://twitter. com/\#!/wiponews. n 